\title{
Multi-instrumentation observations of a transpolar arc in the northern hemisphere
}

\author{
A. Goudarzi ${ }^{1}$, M. Lester ${ }^{1}$, S. E. Milan ${ }^{1}$, and H. U. Frey ${ }^{2}$ \\ ${ }^{1}$ Department of Physics and Astronomy, University of Leicester, Leicester, LE1 7RH, UK \\ ${ }^{2}$ Space Science Laboratory, University of California, Berkeley, CA 94720-7450, USA
}

Received: 4 May 2007 - Revised: 21 November 2007 - Accepted: 9 January 2008 - Published: 4 February 2008

\begin{abstract}
A transpolar arc was imaged by the FUV instrument on the IMAGE spacecraft during a 3 -h interval on 5 February 2002. Observations indicate that a burst of reconnection in the geomagnetic tail, which was not associated with a substorm, was responsible for the formation of the arc. The arc initially formed across the central polar cap, extending from near midnight to noon such that the polar cap was approximately divided in half. The subsequent motion of the arc was controlled by the amount of open flux being added to the dawn sector cap from a magnetopause reconnection site on the post-noon side of the magnetosphere. The dayside reconnection happened during a period when the IMF $B y$ component was dominant, although the $B z$ component initially remained positive, and resulted in strong westward azimuthal flows in the noon sector. The arc continued to move towards the duskside auroral oval after the IMF $B z$ turned southward. A keogram of the FUV/WIC auroral observations along the dawn-dusk meridian provides further evidence of the expansion and contraction of the polar cap during the period in which different IMF orientations occurred. Furthermore, comparing images from IMAGE and ionospheric convection flow from SuperDARN measurements, vortical convection flows occurred exactly at the time and location of the formation of the transpolar arc and subsequently followed the head of the transpolar arc as it moved across the polar cap. The observations are consistent with the prediction of a recent model for the formation of the transpolar cap by the closure of open flux in the geomagnetic tail, and its subsequent motion through changes in the open flux distribution within the polar cap.
\end{abstract}

Keywords. Ionosphere (Polar ionosphere) - Magnetospheric physics (Auroral phenomena; Polar cap phenomena)

Correspondence to: A. Goudarzi

(ag141@ion.le.ac.uk)

\section{Introduction}

Dungey (1963) proposed that whenever the Interplanetary Magnetic Field (IMF) is purely northward, the geomagnetic field of a completely closed model magnetosphere and the IMF become antiparallel and merge tailward of the cusp on field lines that form the tail lobes. Later studies suggested that reconnection between the IMF and open tail lobe magnetic field does not change the total amount of open flux in the magnetosphere as reconnection happens on already open field lines and no open flux will be produced or destroyed (e.g., Russell, 1972; Cowley, 1981; Reiff and Burch, 1985; Cowley and Lockwood, 1992). Recently (Imber et al., 2006) have demonstrated that dual lobe reconnection can cause some flux closure but this occurs only when the IMF clock angle is within $10^{\circ}$ of due northward. IMF northward conditions lead to a range of interesting phenomena in addition to lobe reconnection, however. This study shows the formation and motion of a transpolar arc in the northern hemisphere, which occurred during such northward IMF conditions.

Using the global imaging instrument onboard the Dynamics Explorer 1 spacecraft, Frank et al. $(1982,1986)$ first reported transpolar aurora, i.e. a long-lived auroral structure extending across the polar region, with both ends connecting to the auroral oval, resembling a Greek letter " $\theta$ " (therefore they are also known as theta aurora). The theta aurora, when viewed from high-altitude satellites, appears to be aligned with the Sun, stretching across the entire polar cap, and are also known as transpolar arcs. Transpolar arcs are thought to be the optical manifestation of particle precipitation on closed field lines (Frank et al., 1982, 1986; Zhu et al., 1997). However, other observations, which demonstrate the occurrence of polar rain electrons and relativistic electrons adjacent to and outside of polar cap arc, suggest the arcs are on open field lines, (Hardy et al., 1982; Hardy, 1984; Gussenhoven and Mullen, 1989). A recent study (Eriksson et al., 2005) suggests that the apparent continuous band of

Published by Copernicus Publications on behalf of the European Geosciences Union. 


\section{Feb 2002}

\section{Ace IMF data}

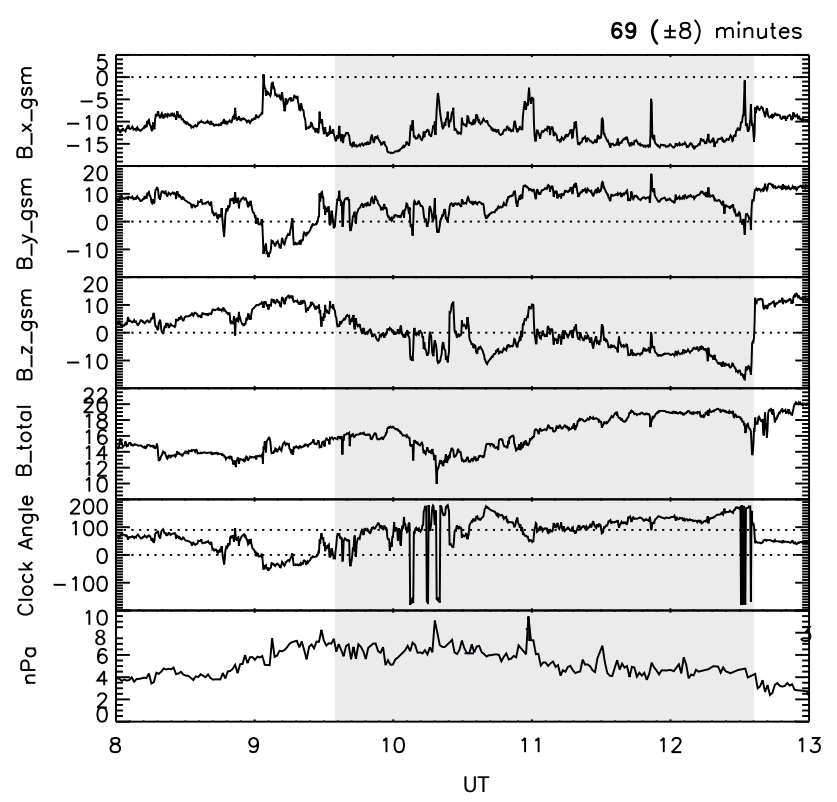

Fig. 1. The interplanetary magnetic field components, $B x, B y$, and $B z$ in GSM coordinates along with the corresponding clock angle and solar wind dynamic pressure, measured by the ACE spacecraft. The measurement was made during a 5-h interval on 5 February 2002. Highlighted in grey is the period when the transpolar arc was observed.

the dayside arc may be considered as two separate entities, one on the dayside and one nightside, driven by two different physical processes. The dayside part of the duskside arc is associated with sunward lobe convection and an upward northward IMF $B z$ current whereas the nightside part of the arc generally tailward of the dawn-dusk meridian is related to an upward field aligned current associated with clockwise convection cells.

Many other studies have been undertaken recently to explain the formation and dynamic characteristics of the transpolar arcs. Previous studies (Cumnock et al., 1997; Kullen et al., 2002, and references therein) have indicated that a majority of transpolar arcs appear during northward IMF, a strong IMF magnitude, and high solar wind speed. Transpolar arcs appear in many different shapes (Kullen et al., 2002). There are some transpolar arcs which are dynamic and move towards either the dusk or dawn side of the oval, while other kinds, such as oval-aligned transpolar arcs, stay on the side of the polar cap where they initially form (Valladares et al., 1994). Both of these kinds, either dynamic or quasi-steady transpolar arcs, appear to be produced at the poleward edge of the duskside (dawnside) auroral oval for positive (nega- tive) IMF $B y$ in the Northern Hemisphere. A few studies have shown that theta aurora can coexist in both hemispheres, with one being the mirror image of the other (Craven et al., 1991; Craven and Frank, 1991; Craven et al., 1986; McEwen and Zhang, 2000). However, another investigation showed cases when the transpolar arc was only observed in one hemisphere and was absent in the other (Ostgaard et al., 2003).

It has been shown that the y-component of the IMF controls the (dawn-dusk) motion of transpolar arcs. After being formed, transpolar arcs can move slowly across the polar cap in the direction of the new IMF $B y$ component in the Northern hemisphere (Frank et al., 1986; Huang et al., 1989; Valladares et al., 1994) and in the opposite direction in the Southern Hemisphere (Craven et al., 1991).

Under northward IMF conditions the polar cap can be divided into two compartments of open flux partitioned by the transpolar arc (Frank et al., 1986; Huang et al., 1987; Zhu et al., 1997; Milan et al., 2005; Frey, 2007), in which case the polar cap will contain two regions of open flux which map to a bifurcated tail lobe. It should be possible for changes in the size of each compartment to occur through the reconnection process under different IMF conditions which can transfer open flux from one compartment to the other. The subsequent expansion of one compartment and correspondingly deflation of the other leads to the motion of the arc (Milan et al., 2005).

In this study we present a case study of a transpolar arc, discuss its formation and also the motion caused by changes in distribution of open flux with the polar cap effected by dayside reconnection. We compare observations of the polar aurora from Imager for Magnetopause-to-Aurora Global Exploration IMAGE FUV/Wide-band Imaging Camera (WIC) instrument (Mende et al., 2000a, b) with simultaneous measurements of the ionospheric convection flow by Super Dual Auroral Radar Network (SuperDARN) (Greenwald et al., 1995). The observations are compared with the theoretical model developed by Milan et al. (2005) to explain the formation of the arc through reconnection in the tail as well as the subsequent motion of the arc in response to dayside reconnection.

\section{Event overview}

\subsection{Interplanetary magnetic field data}

In Fig. 1 we show upstream solar wind and interplanetary magnetic field (IMF) conditions during the interval of interest, 08:00-13:00 UT on 5 February 2002, measured using the SWEPAM and MAG instruments, respectively, on the Advanced Composition Explorer (ACE) satellite (McComas et al., 1998; Smith et al., 1998; Stone et al., 1998). ACE orbits the L1 Lagrangian point at approximately $\mathrm{X} \approx 234 \mathrm{RE}$ (Earth Radii) sunward of the Earth. IMF GSM components are plotted as a function of corrected universal time (UT plus the 
estimated propagation time from the satellite to GSM $\mathrm{X}=0$ ) which for this interval has been calculated as $69 \mathrm{~min}$ using the method of Khan and Cowley (1999). The time period during which the transpolar arc was observed within the polar cap is highlighted in grey in Fig. 1.

The IMF was associated with an away sector Parker spiral magnetic field $(B x<0)$; the total field magnitude was large $(B \sim 16 \mathrm{nT})$. The $B x$ component was negative throughout the whole interval. The $B z$ component was positive for an hour and forty five minutes before it turned negative at approximately 09:40 UT. The $B y$ component was quite variable and changed its direction several times before the arc appeared, which caused the variation in the IMF clock angle before 09:40 UT. As indicated in Fig. 1 (highlighted section), the arc persisted for a period of three hours. There was a sudden change in $B z$ from being strongly negative to strongly positive right after the arc disappeared. This sudden change was also observed in the $B y$ behaviour, as it increased from zero to positive. The solar wind dynamic pressure (Fig. 1, bottom panel) reached a maximum of $9.5 \mathrm{nPa}$ at about 11:00 UT and after that reduced to approximately $3 \mathrm{nPa}$.

\subsection{IMAGE FUV data}

The Far Ultraviolet (FUV) imaging system onboard the IMAGE spacecraft provides global images of the aurora. IMAGE was launched on 25 March 2000 into an elliptical polar orbit with an apogee altitude of 7.2 Earth radii and the perigee altitude of $1000 \mathrm{~km}$. The initial apogee was at $40 \mathrm{de}-$ grees north latitude. The Wideband Imaging Camera (WIC) experiment is one of three detectors installed on the FUV instrument (Mende et al., 2000a, b). The WIC camera is designed to image the whole Earth and the auroral oval from satellite distances greater than $4 \mathrm{RE}$ to the centre of the Earth. It selects the spectral range between $140 \mathrm{~nm}$ and $190 \mathrm{~nm}$ in the ultraviolet part of the optical spectrum.

A sequence of auroral images taken by FUV/WIC on 5 February 2002 during the development of the transpolar arc is presented in Fig. 2a-f. Each panel is presented in a magnetic latitude and MLT coordinate system, with local noon at the top and dusk to the left. Dayglow in the sunlit hemisphere is apparent at the top of each panel 2a-d. In this sequence the transpolar arc is first apparent at about 09:03 UT (Fig. 2b), starting to appear at the point where the aurora is brightest in the premidnight sector. Around 09:43 UT (Fig. 2c) the complete transpolar arc can be observed to lie in the centre of the polar cap, slightly displaced to the dusk (dawn) side on the nightside (dayside). The transpolar arc exists within the polar cap for the next three hours. At 09:54 UT (Fig. 2d), the width of the arc has slightly increased and stays like this for approximately $20 \mathrm{~min}$ before the arc starts to thin again. At 11:10 UT (Fig. 2e), the arc slowly moves towards dusk. The arc continues its duskward motion and by 12:32 UT (Fig. 2f), has moved across the polar region and appears to have merged with the duskward auroral oval. Prior to

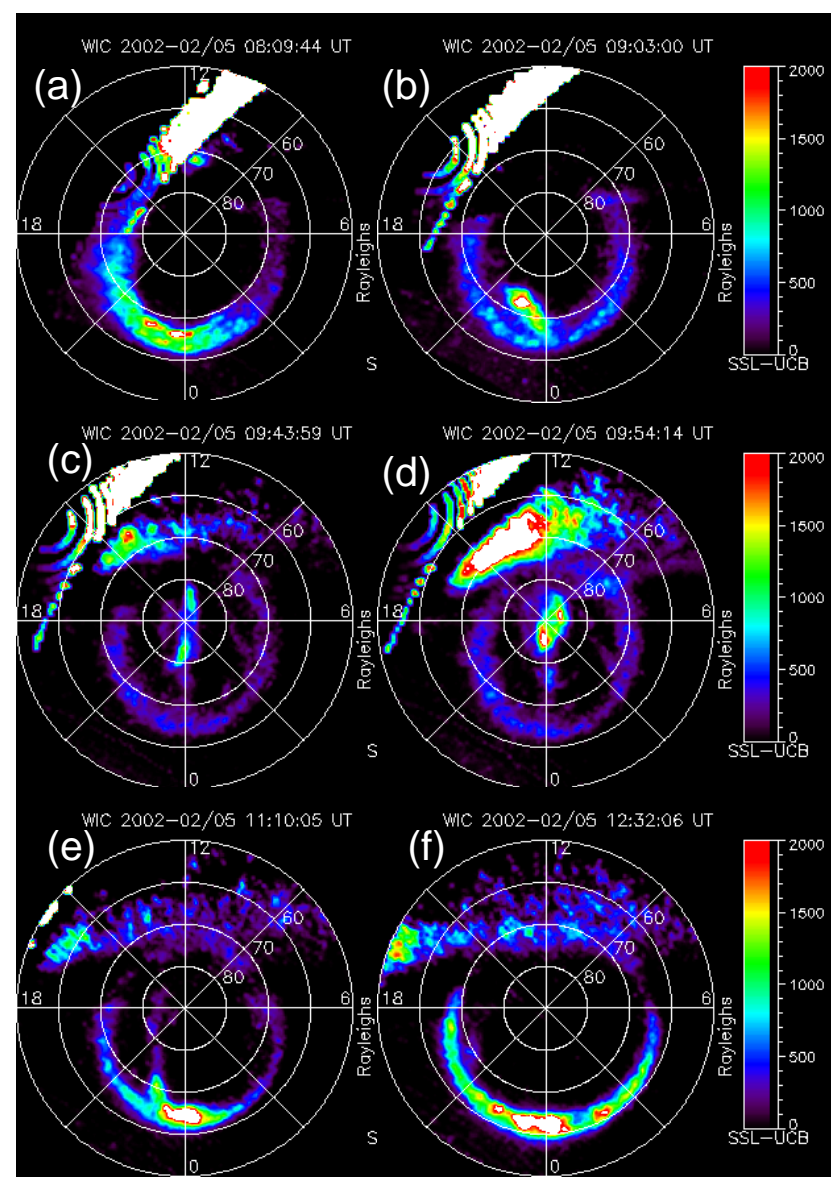

Fig. 2. On 5 February 2002, the Imager for Magnetopause-to- Aurora Global Exploration (IMAGE) FUV/Wide-band Imaging Camera (WIC) instrument provides images of the auroral configuration in the Northern Hemisphere. The data are plotted in magnetic latitude and magnetic local time, with noon toward the top and dusk to the left of each panel.

10:00 UT the auroral oval remains relatively uniform in size, although, by 11:10 UT (Fig. 2e) and especially by 12:32 UT (Fig. 2f), the auroral oval has expanded to lower latitude.

The top panel of Fig. 3 is a keogram of FUV/WIC auroral observations along the dawn-dusk meridian. The motion of the transpolar arc described above and the auroral oval is clearer in this figure. The lower three panels of this figure are the three components of the IMF from ACE spacecraft repeated from Fig. 1. In Fig. 3a the auroral oval is visible in both dusk and dawn sectors, and after 09:30 UT, the transpolar arc is also visible in the middle of the oval. From this observation it is also clear that the auroral oval starts shrinking at about 08:55 UT when the IMF becomes strongly northward. The process goes on until 10:00 UT when $B z$ becomes southward, and the polar cap starts to expand again, moving the auroral oval to lower latitudes. At about 09:36 UT a thick region of auroral luminosity is observed in the centre of the polar cap, the transpolar arc, which gets thinner as it travels towards dusk throughout the interval. 


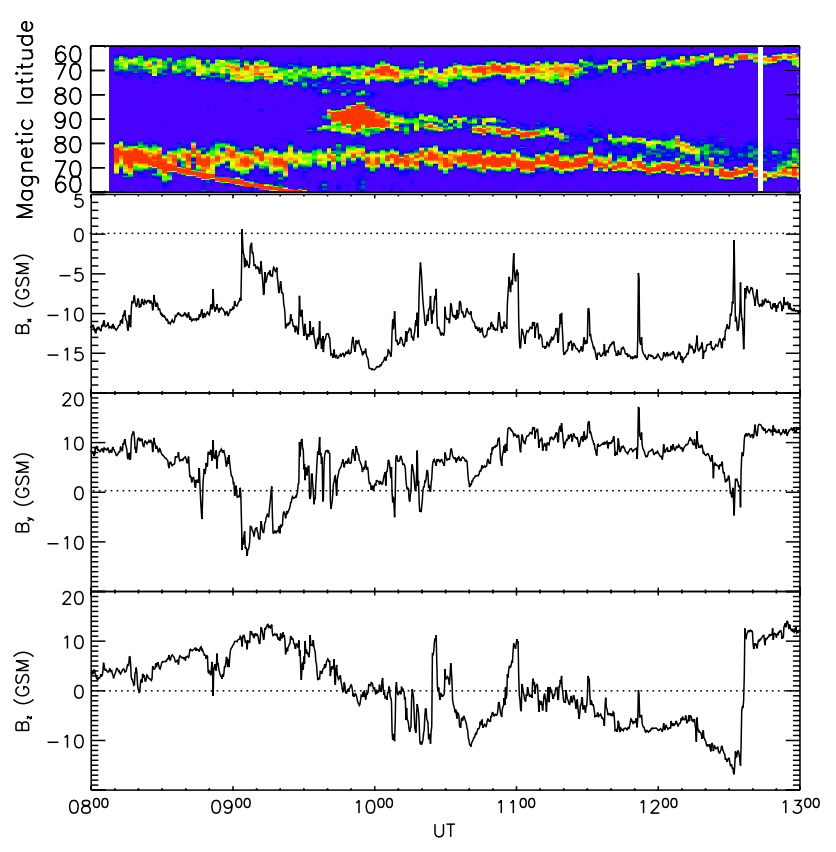

Fig. 3. (a) Keogram presentation of the transpolar arc observed by the IMAGE FUV/WIC along the noon-midnight meridian. (b) IMF clock angle.
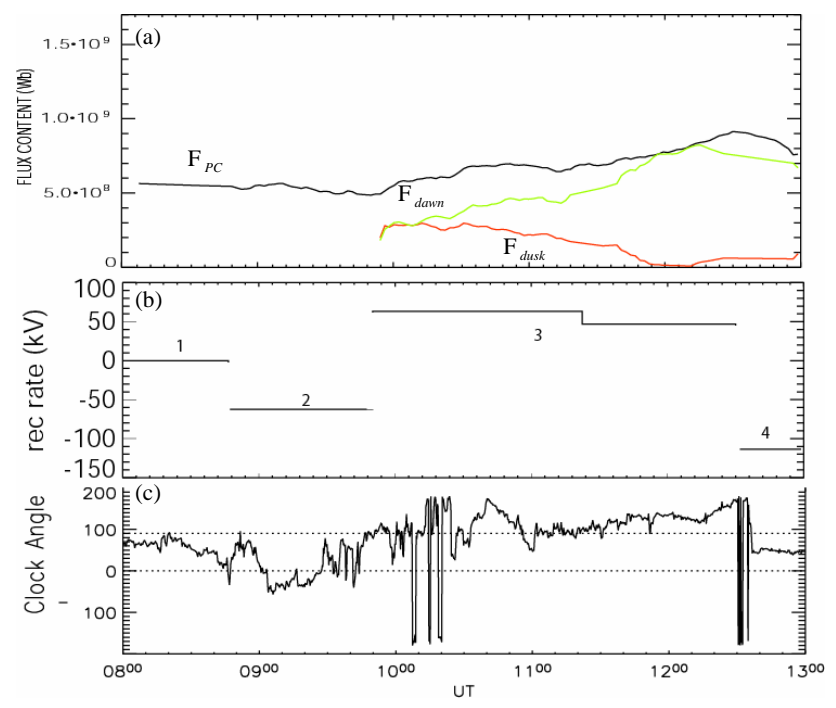

Fig. 4. (a) Total polar cap flux (black curve), and flux contained dawnward (green curve) and duskward (red curve) of the transpolar arc, determined from the auroral observations. (b) Reconnection rates derived from the changes in polar cap flux (see text for more details). (c) IMF $B z$ component.

Using the technique described by Milan et al. (2003), and Milan $(2004 a, b)$, we determined the open flux contained within the magnetosphere from the size of the polar cap in the auroral measurements, and the variation in this as a function of time. The total open flux together with the total open flux in each of the two section of the polar cap, i.e. dawn and dusk sector is presented in Fig. 4a, Fig. 4b shows the rate of change of polar cap area (the difference between dayside and nightside reconnection rate) averaged over specific intervals and Fig. $4 \mathrm{c}$ shows the IMF clock angle. These observations will be discussed in more detail in Sect. 3.1.

\subsection{Ground-based SuperDARN Convection}

Figure 5 shows the ionospheric convection measurements made by the SuperDARN radars, superimposed on the IMAGE auroral observations which were shown in Fig. 2. In order to produce the convection maps, we used 2-min averages of line-of-sight Doppler velocity observations made by eight Northern Hemisphere radars, from which the convection maps were derived using the technique of Ruohoniemi and Baker (1998). In Fig. 5 each map shows the "true" vectors determined by the SuperDARN global convection mapping, colour coded by their magnitude. The black curves represent equipotentials of the convection electric field with little crosses denoting the centres of the convection cells.

Figure 5a, shows convection typical of positive $B y$ and $B z$ conditions. In this figure which is from 08:32 UT there are some sunward flows in the post noon sector indicative of reconnection at the tail lobe. There are two cells which are not symmetrical and slightly biased toward dawn, as a consequence of the IMF By>0, (e.g., Russell, 1972; Cowley, 1981; Reiff and Burch, 1985; Cowley and Lockwood, 1992; Huang et al., 2000; Milan et al., 2000; Chisham et al., 2004). The bright spot in the premidnight sectors is associated with relatively strong eastward flows, similar to these reported by Senior et al. (2002), Grocott et al. (2003, 2004), and Walker et al. (1998). Such flows are usually observed during episodes of magnetotail reconnection happening during extended intervals of northward IMF but with no evidence of substorm activity. These have been termed TRINNIs "tail reconnection during IMF-northward, nonsubstorm intervals", by Milan et al. (2005).

In Fig. 5b there is a vortical flow pattern (anti-sunward flows at higher latitude and sunward flows at lower latitudes) coincident with the brightening in the nightside aurora which seems to be the origin of the transpolar arc. These vortical flows last for $22 \mathrm{~min}$ and vanish right after the change in direction of $B y$ to negative while $B z$ is still positive. There are also some very strong flows at the dayside in the postnoon lobe convection cell. At the time the transpolar arc becomes fully formed (Fig. 5c) the flows seem to be weaker at both dayside and nightside. The auroral oval appears to be displaced toward dawn as $B y$ is still positive. At 09:54 UT (Fig. 5d) the y-component of the IMF is strongly positive, and that is when the width of the arc starts to increase and this process goes on for $12 \mathrm{~min}$. From about 10:32 UT the IMF turns southward again, and that is when very strong anti sunward flows in the postnoon and sunward flows in the prenoon convection cells are observed typical of dayside low latitude 
(a)

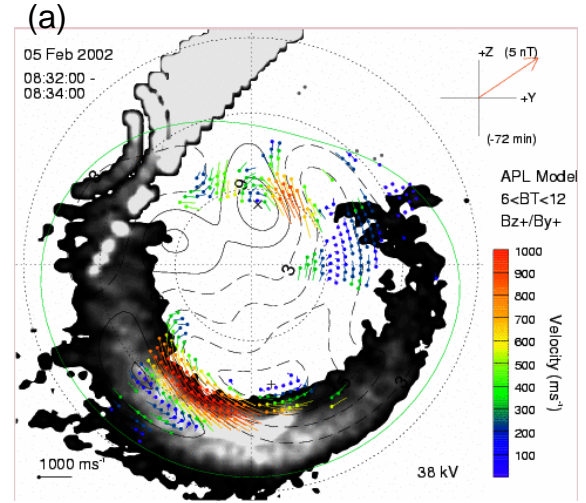

(c)
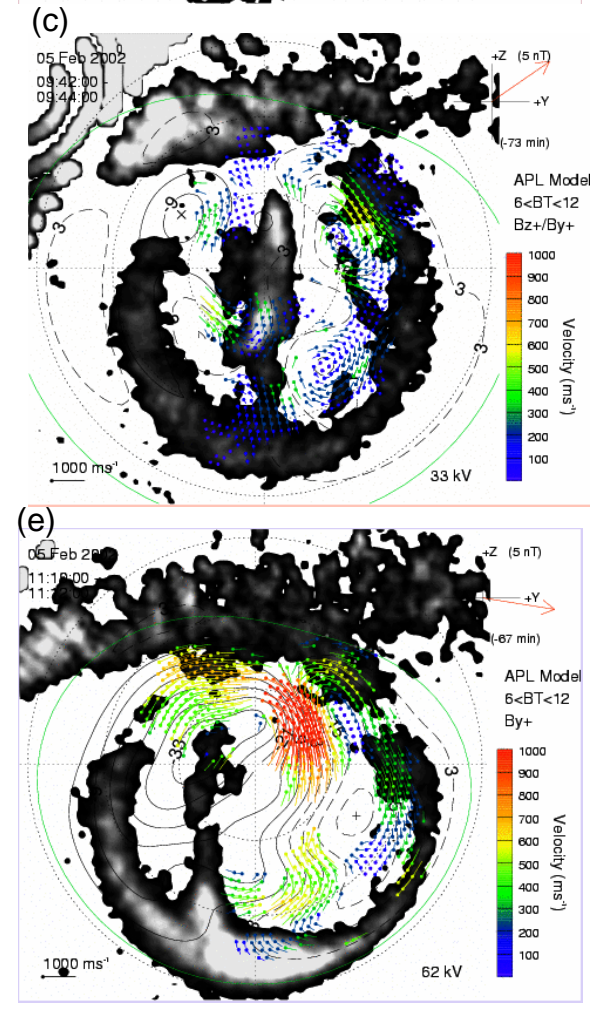

(b)

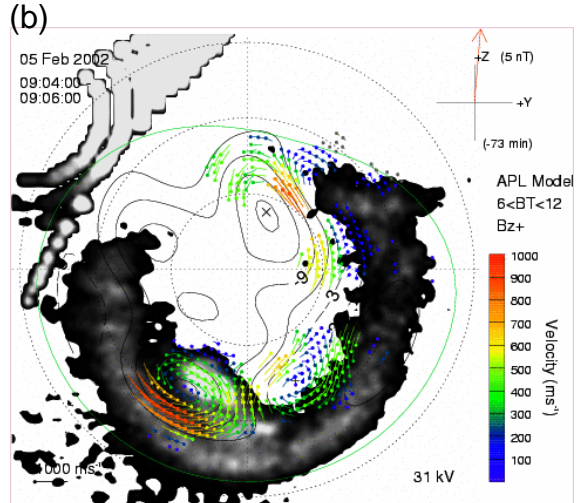

(d)
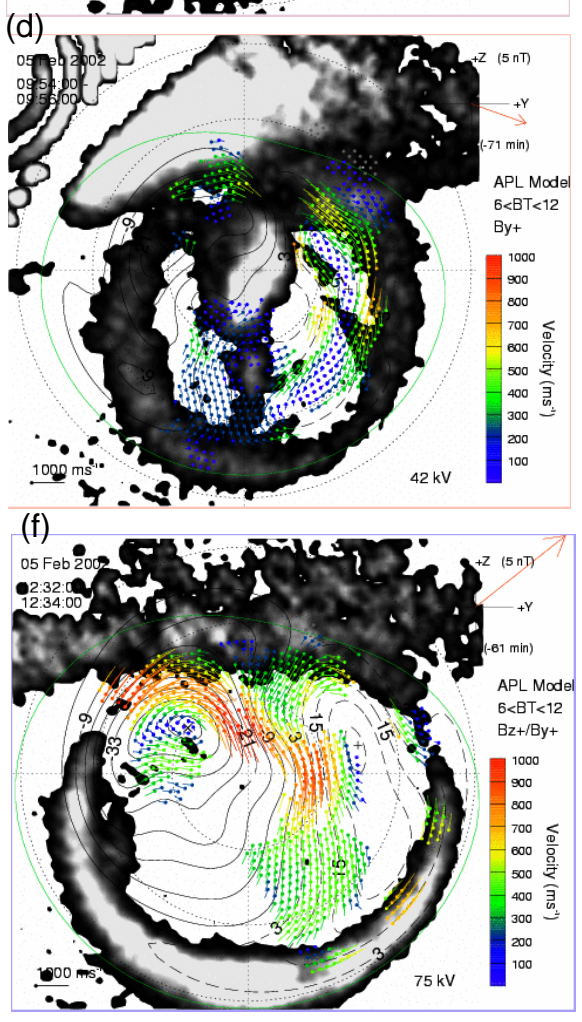

Fig. 5. SuperDARN convection maps with superimposed IMAGE FUV auroral data.

reconnection. However the flows in the dawn-sector polar cap are much stronger than the flows in the dusk sector indicating that new open flux is accumulating on the dawn side of the transpolar arc, which may explain why the arc is getting pushed toward dusk as newly opened magnetic flux is moved towards the dawn sector as can be seen in Fig. 5e. This accumulation of open flux is also associated with the expansion of the auroral oval to lower latitudes. Figure $5 \mathrm{f}$ shows the auroral oval has expanded to lower latitudes by the time the IMF turns northward again after an hour of being southward. From the evidence given it seems that the motion of the arc is governed by the direction of the $B y$ and $B z$ components of the IMF. This motion will be discussed in more detail in Sect. 3.2.

\section{Discussion}

The above description indicates a few important elements to discuss. These are the dynamics of the polar cap and variation of the flux content within the polar cap, the dynamics of the transpolar arc and the relationship to the IMF, and the formation region of the arc and relation to reconnection in the tail. Each of these points is now considered separately in the following discussion.

\subsection{Variation of the polar cap flux content}

In order to look at the dynamics of the polar cap, we first return to the IMF in more detail (Fig. 1). At the start of the interval, $B z$ is quite weak while $B y$ is strongly positive. As 
can be seen from Fig. 3a, the transpolar arc divides the polar cap into two separated sectors, dusk and dawn, both of which contain a certain amount of flux. The flux quantity for both the dawn and dusk sector is determined and shown in Fig. 4a by green and red curves, respectively, along with the total flux content of the polar cap (black curve). In order to study the effects of IMF orientations on the flux contents of the polar cap we have divided the data set into four intervals. As demonstrated in Fig. 4a the total flux content of the polar cap remains constant at about $0.5 \mathrm{GWb}$ between 08:00 and 08:50 UT when the IMF is northward, which suggests that during these positive $B z$ conditions, either there is no reconnection ongoing at the magnetopause and in the tail, or they are exactly balanced, or lobe reconnection is occurring but not changing the amount of flux. After 09:00 UT $B z$ becomes strongly positive and dominates the $B y$ component. It is after this that at the poleward edge of the premidnight aurora an auroral brightening occurs in association with vortical plasma flows (Fig. 5b).

Events termed TRINNIs are an important component of the magnetic flux transfer process within the magnetosphere (Grocott et al., 2003, 2004) and these are indicative of magnetic flux closure in the nightside. Data from the LANL geosynchronous satellites confirms the absence of any substorm activity in the interval of interest. Absence of substorm activity until near 12:30 UT is also confirmed by WIC observations. Due to the closure of the open flux in the magnetotail during the TRINNI event, there is a slight decrease in the open flux content of the magnetosphere of approximately $0.2 \mathrm{GWb}$ which leads to a decrease in the size of the polar cap (Fig. 4). The time-average rate of flux change from 08:30 UT to 09:30 UT indicates a nightside reconnection rate of $\sim 51 \mathrm{kV}$, which we define as a negative rate in Fig. 4 as the polar cap is shrinking.

From about 09:55 UT until 12:35 UT the IMF turns more southward. During this period, the flux content of the polar cap increases to nearly $1 \mathrm{GWb}$ implying a time averaged reconnection rate of approximately $70 \mathrm{kV}$ throughout this interval, although the rate is slightly smaller in the second part of the interval. The southward turning of the IMF at around 09:55 UT causes low-latitude reconnection between closed terrestrial field lines and the IMF which leads to the addition of new flux from one compartment to the other as shown in Fig. 5e and f. This effect is much clearer in Fig. 4a where the flux content of each compartment is shown for dawn sector (green curve) and dusk sector (red curve). Finally at the end of the interval, at 12:35 UT the IMF turns northward again at which time the flux content of the polar cap decreases. This decrease is a result of the substorm associated reconnection of open flux in the magnetotail which started shortly after 12:30 UT; an auroral brightening is seen in Fig. 2e-f. The reconnection rate changes to $-110 \mathrm{kV}$. The dynamics of the polar cap during this interval and the subsequent motion of the auroral oval, therefore, are controlled by reconnection processes in both the tail and at the dayside magnetopause.
In this interval reconnection in the tail occurs first during a period when there was no substorm activity and then later as a result of substorm activity following a period of southward IMF. The reconnection potential associated with the substorm is of order twice that associated with the TRINNI.

\subsection{Formation and motion of the transpolar arc}

At about 09:00 UT the transpolar arc forms at the poleward edge of the auroral oval. This brightening is coincident with vortical flows shown in Fig. 5b. This brightening occurs slightly poleward of the TRINNI and the flow does appear to change from azimuthal to vortical.

Milan et al. (2005) surmised that during TRINNIs, reconnection of the magnetic field lines in the tail creates new closed field lines which are not contained in the meridian plane of the tail, but connected to the dawn and dusk ionospheres in opposite hemispheres. Under normal circumstances when a tail reconnection X-line forms, the resulting closed field lines are contained in meridian planes, and as they contract and convect around the Earth toward the dayside, they generate dawnward and duskward return flow in the nightside ionosphere symmetrically about the noonmidnight meridian (Fig. $6 \mathrm{~b}$ and c). The topology associated with the TRINNI however, results in strong westward flow across the midnight meridian in the case of $B y<0$, in the midnight sector of the Northern Hemisphere ionosphere. The Southern Hemisphere end of the field lines map to the dusk sector ionosphere and need only convect slowly in the return flow. Correspondingly, in the dawn sector of the Northern Hemisphere, slow or stagnant eastward return flow is expected as the southern hemisphere ends of these field lines attempt to catch up with the vigorous eastward flow in the midnight sector. However, the field line that maps to the noon-midnight meridian in the equatorial plane faces competition between the Northern and Southern Hemispheres, as both ends of this field line cannot simply convect sunward in the return flow region as is the case in simpler field geometries.

However in this case study, the transpolar arc forms during $B y>0$, and when the opposite direction of the ionospheric flows is observed, again as predicted by Milan et al. (2005). In this case study the transpolar arc is formed in the region where closed field lines are accumulated in return flows stymied by opposing tension between the opposite hemispheres. This region corresponds to the western end of a strong eastward convection jet for IMF $B y>0$ (Fig. 6c).

During the formation of the transpolar arc, the $y$ component of the IMF is positive and larger in magnitude than the $B z$ component which remains mainly positive. Two convection cells are formed with one larger than the other, "orange" and "banana" shaped cells which are slightly biased toward dawn. From about 09:55 UT the polar cap expands implying dayside reconnection dominates over nightside reconnection at this time. During this time the flow at the 
dayside is strongly azimuthal due to the large $B y$ component with the flow going from post noon to pre-noon (e.g. Fig. 5e). In the theoretical model proposed by Milan et al. (2005), the arc motion was governed by siphoning open flux from one side of the arc to the other by lobe reconnection. In the present case the mechanism is similar, i.e. motion being caused by a redistribution of open flux. However the redistribution is caused by addition and subsequent accumulation of open flux on one side of the arc only by $B y$ dominated low latitude reconnection. In this case, the dayside reconnection adds open flux to the dawn cell of the polar cap, inflating the dawn sector polar cap and also causing the polar cap to expand.

Although this theoretical model sounds completely reasonable for the formation of the transpolar arc, there seems to be another phenomenon which is associated with the formation of the transpolar arc in this interval and that is the vortical flow at the westward edge of the nightside auroral oval. These vortical flows seem to be located close to the origin of the transpolar arc and they accompany the arc all the way into the polar cap and disappear as soon as the arc forms completely (Fig. 7, red ovals), but it is not at this stage clear how they fit the above model for the formation of the TRINNI. Eriksson et al. (2005) observed a clockwise lobe convection vortex at the dayside part of a transpolar arc which was associated with upward field aligned current sheet. They proposed that as the quasi-continuous lobe reconnection sustains the dayside oval-aligned transpolar arc, the transpolar arc of interest lies on open field lines, which is in disagreement with our proposed model. Considering all the evidence given earlier we can conclude that the transpolar arc of interest is one continuous band which lies on closed field lines. This, however, is not in agreement with the theoretical model proposed by (Eriksson et al., 2005) on the formation of transpolar arc, as their theoretical model suggested a division in the ovalaligned transpolar arcs into two separate entities, one on the dayside and one nightside, driven by two different physical processes. Eriksson et al. (2005) also suggested as a consequence that there would be strong shear in the plasma flow associated with the transpolar arc. However, the ionospheric flow measured by the SuperDARN radars in this case study demonstrates no shear in the plasma flow at the location of the transpolar arc. Thus we conclude that the transpolar arc lies on closed field lines.

\section{Summary}

In this paper we have presented, a detailed multi-instrument study of a transpolar arc in the northern hemisphere under different IMF orientations. Milan et al. (2005) suggested that the motion of the arc can be controlled by various factors such as reconnection processes and the IMF orientations. In their theoretical model, a case study was presented where due to different IMF conditions, different types of reconnection a

b
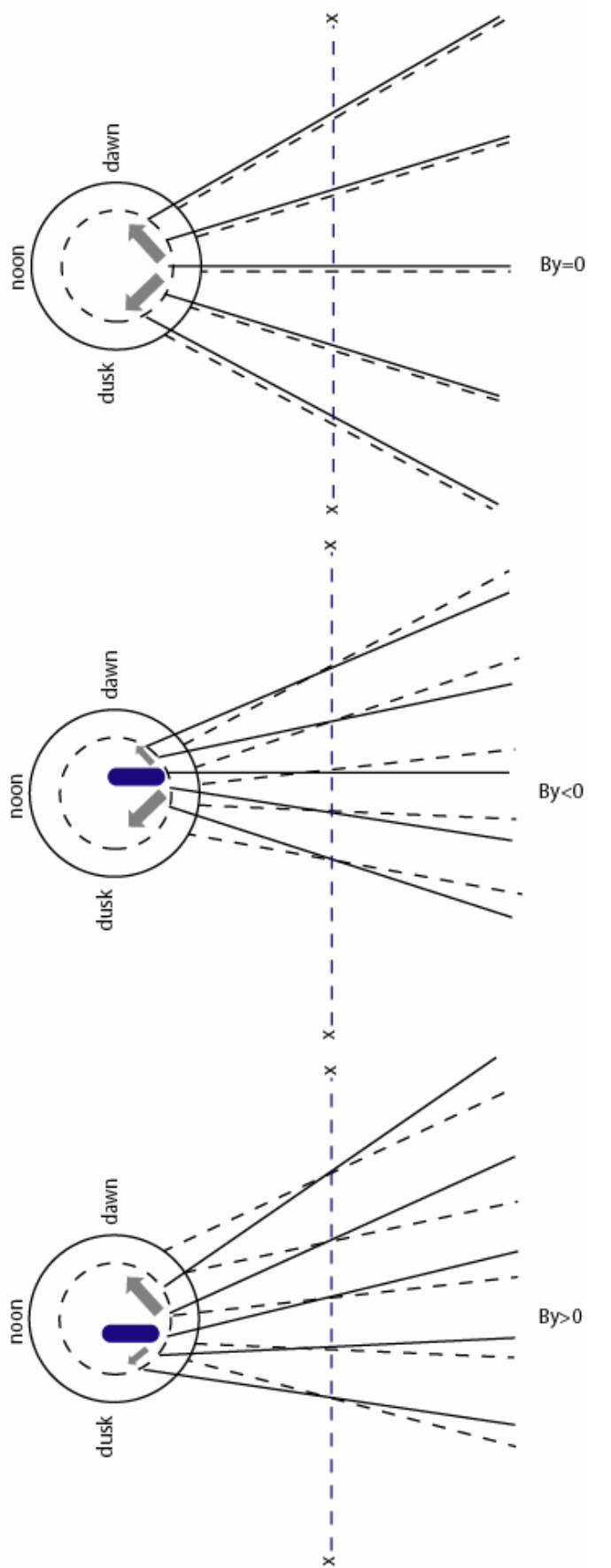

Fig. 6. Schematic diagrams to show the field topologies in the magnetotail after reconnection for (a) IMF $B y=0$ (b) $B y<0$ and (c) $B y>0$. Dashed circle indicates the polar cap, and solid (dotted) lines represent nightside field lines for the Northern an (Southern) Hemisphere. Convection return flows in the equatorial plane of the tail and in the ionosphere are shown using arrows. In Fig. $6 \mathrm{~b}$ and c, opposing forces in the Northern and Southern hemispheres results in the formation of transpolar arcs shown with blue rectangles (based on Fig. 6, Milan et al., 2005). 
(a)

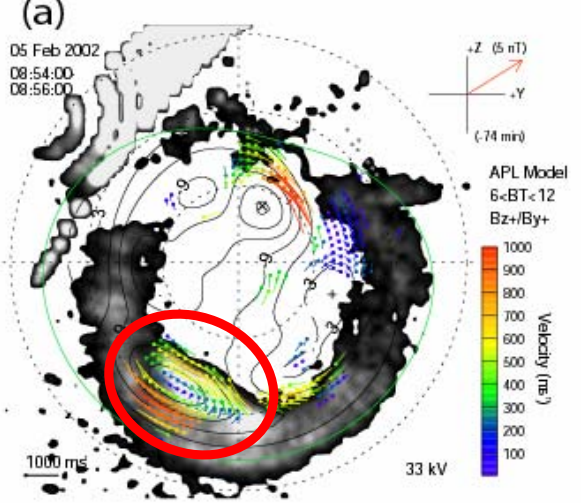

(c)

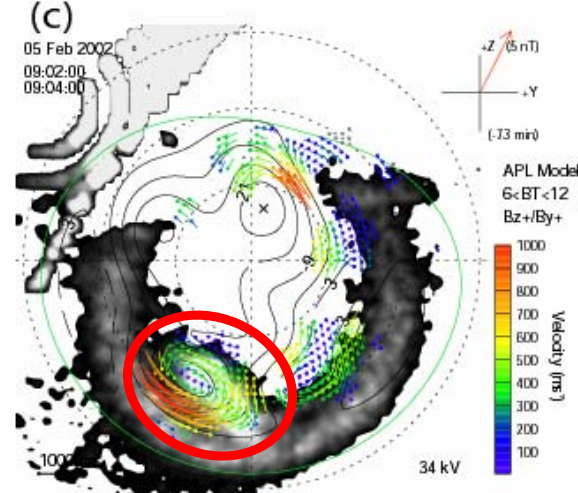

(e)

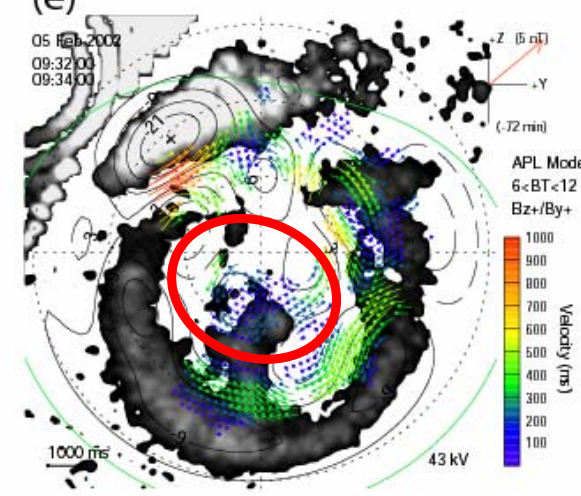

(b)
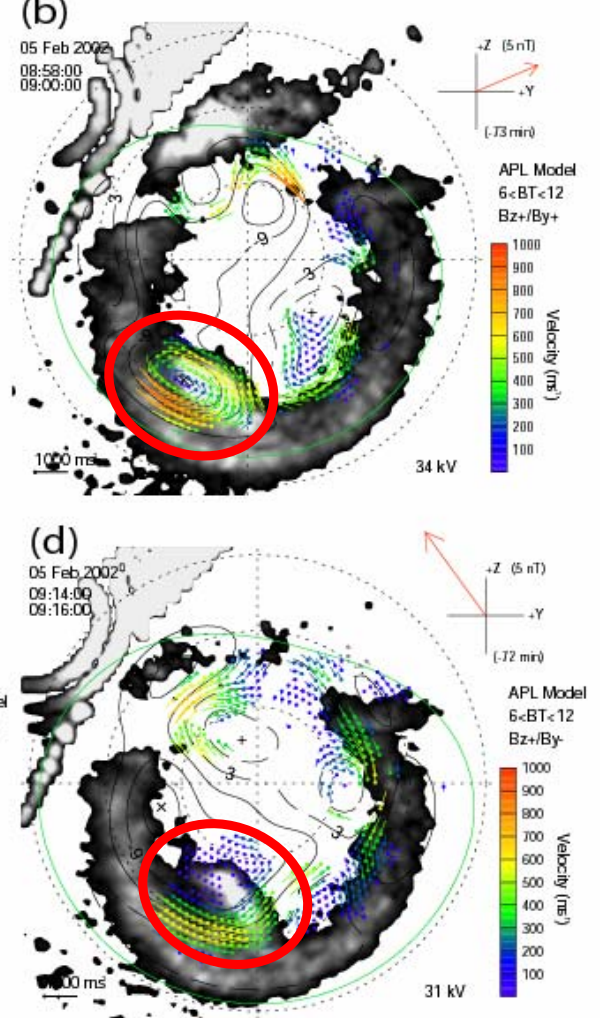

(f)

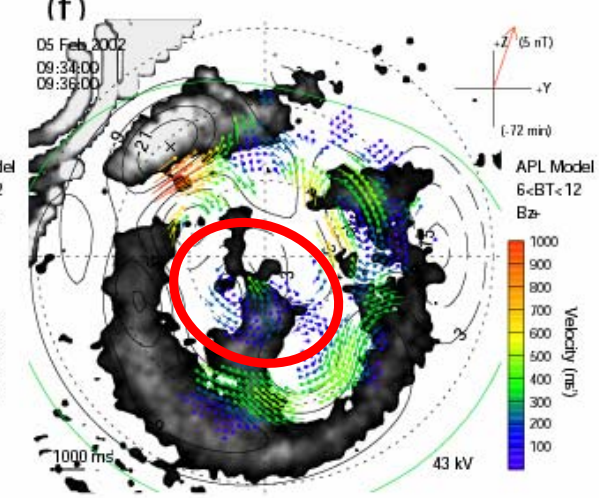

Fig. 7. SuperDARN convection maps with superimposed IMAGE FUV auroral data. Marked with red ovals are locations of the vortical flows.

occurred (e.g. high- and low-latitude reconnection) resulting in motion of the arc and makes the arc to move. What makes our results noteworthy is the variable IMF orientations and visible effects of this variation on the formation and dynamics of the transpolar arc.

The summary of this study is as follows:

1. The formation of the transpolar arc is initiated by reconnection of magnetic flux in the tail which also forms the fast azimuthal flow (TRINNI) across magnetic midnight.

2. Some nightside vortical flows seem also to be associated with the origin of the arc and accompany the arc into the polar cap.

3. Subsequent motion of the arc is caused by both the redistribution of open flux in the magnetotail lobes, as well as the addition of newly open flux added by low latitude reconnection.

4. No apparent flow shear is associated with the transpolar arc within the polar cap.

The work indicates a consistency with the model for transpolar arc formation proposed by Milan et al. (2005) which 
places the arc on closed magnetic field lines. Further examples are being investigated to demonstrate that this model can explain transpolar arc formation and dynamics under a variety of conditions.

Acknowledgements. The ACE data used in this study were accessed through CDAweb. We would like to thank N. F. Ness at the Bartol Research Institute and D. J. McComas of the Southwest Research Institute for use of the MAG and SWEPAM data, respectively. We would like to acknowledge the principle investigators of the SuperDARN project for use of their data. M. Lester and S. E. Milan are supported by STFC grant PP/E000983. A. Goudarzi would also like to thank DHPA for their valuable support.

Topical Editor I. A. Daglis thanks two anonymous referees for their help in evaluating this paper.

\section{References}

Chisham, G., Freeman, M. P., Coleman, I. J., Pinnock, M., Hairston, M. R., Lester, M., and Sofko, G.: Measuring the dayside reconnection rate during an interval of due northward interplanetary magnetic field, Ann. Geophys., 22, 4243-4258, 2004,

http://www.ann-geophys.net/22/4243/2004/.

Cowley, S. W. H.: Magnetospheric and ionospheric flow and the interplanetary flow and the interplanetary magnetic field, in The Physics Basics of the Ionosphere in the solar-terrestrial system, AGARD Conf. Proc., CP-295, 4, 1-14, 1981.

Cowley, S. W. H. and Lockwood, M.: Excitation and decay of solar wind driven flows in the magnetosphere-ionosphere system, Ann. Geophys., 10, 103-115, 1992,

http://www.ann-geophys.net/10/103/1992/.

Craven, J. D., Frank, L. A., Russell, C. T., Smith, E. J., and Lepping, R. P.: Global auroral responses to magnetospheric compressions by shocks in the solar wind: Two case studies, in: Solar WindMagnetosphere Coupling, edited by: Kamide, Y. and Slavin, J. A., 377-380, Terra Scientific Publ. Co., Tokyo, 1986.

Craven, J. D., Murphree, J. S., Frank, L. A., and Cogger, L. L.: Simultaneous optical observations of transpolar arc in the two polar caps, Geohys. Res Lett., 18, 2297-2300, 1991.

Craven, J. D. and Frank, L. A.: Diagnosis of auroral dynamics using global auroral imaging with emphasis on large-scale evolution, in: Auroral Physics, edited by: Meng, C.-I., Rycroft, M. J., and Frank, L. A., Cambridge University Press, Cambridge (English), 273-288, 1991.

Crooker N. U.: Reverse convection, J. Geophys. Res., 97, 1936319372, 1992.

Cumnock, J. A., Sharber, J. R., Heelis, R. A., Hairston, M. R., and Craven, J. D.: Evolution of the global aurora during positive IMF $\mathrm{Bz}$ and varying IMF By conditions, J. Geophys. Res., 102(17), 489-497, 1997.

Dungey, J. W.: The structure of the exosphere, or adventures in velocity space, in Geophysics: The Earth's environment, edited by: DeWitt, C., Hieblot, J., and Lebeau, A., Gordon and Breach, Newrk, N. J., 503-550, 1963.

Eriksson, S., Baker, J. B. H., Petrinec, S. M., Wang, H., Rich, F. J., Kuznetsova, M., Dunlop, M. W., Reme, H., Greenwald, R. A. Frey,, H. U., Luhr, H., Egun, R. E., Balogh, A., and Carlson, C. W.: On the generation of enhanced sunward convection and transpolar aurora in the high-latitude ionospheric by magnetic merging, J. Geophys. Res., 110(A11), A11218, doi:10.1029/2005JA011149, 2005.

Frank, L. A., Craven, J. D., Burch, J. L., and Winningham, J. D.: Polar views of the Earth's aurora with Dynamics Explorer, Geophys. Res. Lett., 9, 1001-1004, 1982.

Frank, L. A., Gurnet, D. A., Shawhan, S. D., Weimer, D. R., Burch, J. L., Winningham, J. D., Chappell, C. R. , Waite, J. H., Heelis, R. A., Maynard, N. C., Sugiura, M., Peterson, W. K., and Shelley, E. G.: The theta aurora, J. Geophys. Res., 91, 3177-3224, 1986.

Frey, H. U.: Localized aurora beyond the auroral oval, Rev. Geophys., 45, RG1003, doi:10.1029/2005RG000174, 2007.

Greenwald, R. A., Baker, K. B., Dudeney, J. R., Pinnock, M., Jones, T. B., Thomas, E. C., Villain, J.-P., Cerisier, J. C., Senior, C., Hanuise, C., Hunsucker, R. D., Sofko, G., Koehler, J., Nielsen, E., Pellinen, R., Walker, A. D. M., Sato, N., and Yamagishi, H.: DARN/SuperDARN: A global view of the dynamics of highlatitude convection, Space Sci. Rev., 71, 761-769, 1995.

Grocott, A., Cowley, S. W. H., and Sigwarth, J. B.: Ionospheric flow during extended intervals of the northward but By-dominated IMF, Ann. Geophys., 21, 509-538, 2003, http://www.ann-geophys.net/21/509/2003/.

Grocott, A., Badman, S. V., Cowley, S. W. H., Yeoman, T. K., and Cripps, P. J.: The influence of IMF By on the nature of the nightside high-latitude ionospheric flow during intervals of positive IMF Bz, Ann. Geophys., 22, 1755-1764, 2004, http://www.ann-geophys.net/22/1755/2004/.

Gussenhoven, M. S. and Mullen, E. G.: Simultaneous relativistic electron and auroral particle access to the polar caps during interplanetary magnetic field Bz northward: A scenario for an open field line source of auroral particles, J. Geophys. Res. 94, 17121 $17132,1989$.

Hardy, D. A., Burke, W. J., and Gussenhoven, M. S.: DMSP optical and electron measurements in the vicinity of polar cap arcs, J. Geophys. Res., 87, 2413-2430, 1982.

Hardy D. A.: Intense fluxes of low-energy electrons at geomagnetic latitudes above 85 , J. Geophys. Res., 89, 3883-3892, 1984.

Huang, C. Y., Frank, L. A., Peterson, W. K., William, D. L., Lennartsson, W., Mitchell, D. G., Elphic, R. C., and Russell, C. T.: Filamentary structures in the magnetotail lobes, J. Geophys. Res., 92, 2349-2363, 1987.

Huang, C. Y., Craven, J. D., and Frank, L. A.: Simultaneous observations of a theta aurora and associated magnetotail plasma, J. Geophys. Res., 94(A8), 10 137-10143, 1989.

Huang, C. Y., Sofko, G. J., Koustov, A. V., Andre, D. A., Ruohoniemi, J. M., Greenwald, R. A., and Hairston, M. R.: Evolution of ionospheric multicell convection during northward interplanetary magnetic field with Bz/By > 1, J. Geophys. Res., 105, 27 095-27 107, 2000.

Imber, S. M., Milan, S. E., Hurbert, B.: The auroral and ionospheric flow signatures of dual lobe reconnection, Ann. Geophys., 24, 3115-3129, 2006, http://www.ann-geophys.net/24/3115/2006/.

Khan, H. and Cowley, S. W. H.: Observations of the responses time of high latitude ionospheric convection to variations in the interplanetary magnetic field using EISCAT and IMP-8 data, Ann. Geophys., 17, 1306-1335, 1999, http://www.ann-geophys.net/17/1306/1999/.

Kullen, A., Brittnacher, M., Cumnock, J. A., and Blomberg, L. G.: Solar wind dependence of the occurrence and motion of polar au- 
roral arcs: A statistical study, J. Geophys, Res., 107(A11), 1362, doi:10.1029/2002JA009245, 2002.

McComas, D. J., Bame, S. J., Barker, P., Feldman, W. C., and Philips, J. L.: Solar wind electron proton alpha monitor (SWEPAM) for the Advance Composition Explorer, Space Sci. Rev., 86, 563-612, 1998.

McEwen, D. J. and Zhang, Y.: A continuous view of the down-dusk polar cap, Geophys. Res. Lett., 27, 477-480, 2000.

Mende, S. B., Heetderks, H., and Frey, H. U.: Far ultraviolet imaging from the IMAGE spacecraft 1. System design, Space Sci. Rev., 91, 243-270, 2000a.

Mende, S. B., Heetderks, H., and Frey, H. U., et al.: Far ultraviolet imaging from the IMAGE spacecraft. 2. Wideband FUV imaging, Space Sci. Rev., 91, 271-285, 2000b.

Milan, S. E., Lester, M., Cowley, S. W. H., and Brittnacher, M.: Dayside convection and auroral morphology during an interval of Northward interplanetary magnetic field, J. Geophys. Res., 105, 15 741-15 755, 2000.

Milan, S. E., Lester, M., Cowley, S. W., Oksavik, K., Brittnacher, M., Greenwald, R. A., Sofko, G., and Villain, J.-P.: Variations in the polar cap area during two substorm cycles, Ann. Geophys., 21, 1121-1140, 2003, http://www.ann-geophys.net/21/1121/2003/.

Milan, S. E., Cowley, S. W. H., Lester, M., Wright, D. M., Slavin, J. A., Fillinghim, M., Carlson, C. W., and Singer, H. J.: Response of the magnetotail to changes in the open flux content of the magnetosphere, J. Geophys. Res., 109, A04220, doi:10.1029/2003JA010350, 2004a.

Milan, S. E.: Dayside and nightside contributions to the cross polar cap potential: Placing an upper limit on a viscous-like interaction, Ann. Geophys., 22, 3771-3777, 2004b.

Milan, S. E., Hubert, B., and Grocott, A.: Formation and motion of a transpolar arc in response to dayside and nightside reconnection, J. Geophys. Res., 110, A01212, doi:1029/2004JA010835, 2005.
Ostgaard, N., Mende, S. B., Frey, H. U., Frank, L. A., Sigwarth, J. B.: Observations of non-conjugate theta aurora, Geophys. Res. Lett., 30(21), 2125, doi:10.1029/2003GL017914, 2003.

Reiff, P. H. and Burch, J. L.: IMF By-dependent plasma flow and Birkeland currents in the dayside magnetosphere: 2. A global model for northward and southward IMF, J. Geophys. Res., 90, $1595-1609,1985$.

Ruohoniemi, J. M. and Baker, K. B.: Large-scale imagine of high latitude convection with Super Dual Auroral Radar Network HF radar observations, J. Geophys. Res., 103, 20 797-20 811, 1998.

Russell, C. T.: The configuration of the magnetosphere, in Critical problems of Magnetospheric Physics, edited by: Dyer, E. R., p. 1, Inter-Union Comm. On Sol. Terr. Phys., Natl. Acad. Of Sci., Washington. D. C., 1972.

Senior, C., Cerisier, J.-C., Rich, F., Lester, M., and Parks, G. K. Strong sunward propagation flow bursts in the night sector during quiet solar wind conditions, SuperDARN and satellite observations, Ann. Geophys., 20, 771-779, 2002, http://www.ann-geophys.net/20/771/2002/.

Smith, C. W., L'Heureux, J., Ness, N. F., Acuna, M. H., Burlaga, L. F., and Scheifele, J.: the ACE Magnetic Field Experiment, Space Sci. Rev., 86, 613-632, 1998.

Stone, E. C., Frandsen, A. M., Mewaldt, R. A., Christian, E. R., Margolies, D., and Ormes, J. F.: The Advance Composition Explorer, Space Sci. Rev., 86, 1-22, 1998.

Valladares, C. E., Carlson, H. C., and Fukui, K.: Interplanetary magnetic field dependency of stable Sun-aligned polar cap arcs, J. Geophys. Res., 99, 6247-6272, 1994.

Walker, A. D. M., Pinnock, M., Baker, K. B., Dudeney, J. R., and J. P. S.: Strong flow bursts in the nightside ionosphere during extremely quiet solar wind conditions, Geophys. Res. Lett., 25(6), 881-884, 1998.

Zhu, L., Schunk, R. W. and Sojka, J. J.: Polar cap arcs: A review, J. Atmos. Sol.-Terr. Phy., 59, 1087-1126, 1997. 